\title{
DESENVOLVIMENTO ECONÔMICO NA MICRORREGIÃO DE FREDERICO WESTPHALEN (RS)
}

Carlos Eduardo Arns*

Leonel Piovezana**

\begin{abstract}
Resumo
O artigo sobre desenvolvimento na microrregião de Frederico Westphalen (RS), foi construído a partir de uma proposta metodológica e de sua aplicabilidade, possibilitando a compreensão e a identificação do potencial e dos estrangulamentos do processo de desenvolvimento, bem como para a reflexão dos autores locais. Para a compreensão da temática, tratamos da região como palco do desenvolvimento local e de existência concreta de potencialidades de um desenvolvimento endógeno em regiões rurais a partir da análise dos três macrossetores (agropecuária; indústria e serviços); da identificação dos subsetores "grandes" e destes os considerados "básicos" ou com potencial exportador, mas que são específicos da região, para o qual se utilizou o Quociente Locacional - QL; na identificação dos possíveis encadeamentos e na hierarquização dos setores com algum potencial, pela alta expressão do QL, ou seja, forte potencial exportador e impulcionador da dinâmica endógena da economia local. A microrregião possui uma área de $5.271 \mathrm{~km}^{2}$, com uma população de 180.174 habitantes em 2007, apresentando uma taxa de crescimento de $0,75 \%$ ao ano no período de 2000/ 2007, constituída por 27 municípios, que neste estudo foram apontadas as potencialidades e limites para o desenvolvimento econômico. A análise dos QLs, apontam a região, como essencialmente agrícola, com atividades de potencial para desenvolvimento endógeno (específicas) de produção e de diferencial socioeconômico.
\end{abstract}

Palavras-chave: desenvolvimento, metodologia, potencial.

\footnotetext{
* Agrônomo, Professor do curso de Agronomia da Unochapecó; Especialista em Administração Rural; Mestrando em Desenvolvimento Regional pela UNISC de Santa Cruz do Sul (RS). Atua na área de desenvolvimento Rural/Territorial com consultoria em temáticas como: Extensão Rural, Cooperação Agrícola, Planejamento Rural, Agroecologia e Agricultura Familiar. ** Graduado em História Estudos Sociais pela Faculdade de Filosofia Ciências e Letras de Palmas (1984), Especialista em História e Geografia pela UFSC e mestre em Desenvolvimento Regional - Área sociocultural, pela Universidade de Santa Cruz do Sul (2000). Professor da Universidade Comunitária Regional de Chapecó e doutorando em Desenvolvimento Regional pela UNISC de Santa Cruz do Sul (RS).
} 


\section{Introdução}

O presente texto tem por objetivo descrever sucintamente a proposta metodológica de identificação e mobilização do potencial de desenvolvimento endógeno de uma região. Têm origem nas discussões e no trabalho apresentado na disciplina Teorias e Políticas de Desenvolvimento Econômico Regional, do Programa de Pós-Graduação em Desenvolvimento Regional, Mestrado e Doutorado, da UNISC (RS).

Busca-se identificar o potencial e os estrangulamentos do processo de desenvolvimento econômico da microrregião de Frederico Westphalen (RS), aplicando apenas parte da proposta metodológica desenvolvida por Paiva (2004).

Cabe ressaltar que o texto possibilita compreender a importância da proposta metodológica e sua aplicabilidade, por trazer à "luz" alguns dos importantes elementos no debate do desenvolvimento para a reflexão dos autores locais.

O documento, em seu segundo item, aponta alguns dos principais pressupostos teóricos que orientam a construção do estudo; no terceiro item, apresenta-se um breve apanhado da proposta metodológica de identificação e mobilização de potencial de desenvolvimento endógeno de uma região; no quarto item, descrevem-se as principais características socioeconômicas da microrregião de Frederico Westphalen; no quinto item, sintetizam-se algumas das potencialidades e estrangulamentos possíveis de visualizar a partir dos dados secundários analisados; por fim, são tecidas algumas considerações finais, buscando evidenciar os elementos para o debate dos atores locais.

\section{Região e o desenvolvimento local}

Há um relativo consenso sobre os limites e a insustentabilidade do atual modelo de desenvolvimento, principalmente em suas dimensões ambiental, social e cultural.

A noção de desenvolvimento para um conjunto de organizações sociais dos três estados do Sul, constituída a partir de suas experiências concretas, estudadas por Arns e colaboradores (2004, p. 21), é permeada por várias qualificações, conforme segue: a dimensão endógena, que propõe construir o desenvolvimento de baixo para cima e de dentro para fora, em contraposição ao desenvolvimento imposto de cima para baixo e de fora para dentro; a ênfase na autonomia dos grupos populares, conquistada através da participação cidadã; um projeto de 
desenvolvimento que gere inclusão social, política, econômica e ambiental forjado a partir e com a participação dos sujeitos sociais, que historicamente estiveram à margem de processos com estas pretensões; uma visão multidimensional do desenvolvimento com visível tensionamento da questão social como orientadora dos rumos do processo de desenvolvimento a se gerar.

Do mesmo modo e em muitos casos integrados, crescem nestas últimas duas décadas o debate e a construção de experiências sobre abordagens de desenvolvimento rural, contrapondo-se à visão ainda dominante da subordinação do rural ao urbano/industrial por sua incapacidade de promover dinâmicas de desenvolvimento.

Estudos sobre a ruralidade ${ }^{1}$ em países europeus, desenvolvidos pela OCDE (Oganization for Economic Co-Operation and Development), surpreendentemente evidenciaram que muitas regiões essencialmente rurais geraram mais empregos que as essencialmente urbanas, eram as regiões relativamente rurais onde mais cresciam os empregos, levando a compreensão de que ruralidade não é mais sinônimo de atraso (ABRAMOVAY, 2003; VEIGA, 2007).

Não é objetivo aqui dissertar sobre a importante discussão acerca de região, seus conceitos, sentidos, significados e usos. Mas para o objetivo proposto partimos do mesmo entendimento de Paiva e Tartaruga de que "as regiões têm existência concreta", e, mais, existem diversas "regiões reais" (grifos dos autores) subordinadas diretamente aos objetivos de quem regionaliza. No entanto, isto não a torna arbitrária, pois, segundo os mesmos autores, uma boa regionalização é aquela adequada, consistente a seus fins e, portanto, passa a ser uma questão estritamente científica. Por outro lado, "os próprios fins impõem regionalizações como meio [...], que traduzem demandas sociais de apropriação teórica e prática dos territórios, que tem determinações reais e materiais" (PAIVA; TARTARUGA, 2007, p. 22).

\section{Para uma proposta metodológica de identificação de potencialidades de um desenvolvimento endógeno em regiões rurais}

Para Paiva (2004), identificar o "potencial” de uma região é identificar aqueles setores que, uma vez mobilizados/fomentados, geram o maior benefício por unidade de custo, para o qual o mesmo autor apresenta três determinantes fundamentais do "potencial regional", conforme segue: 1) a capacidade de crescimento sustentável da produção e da renda apropriada internamente; 2) a condição de mobilização
${ }^{1}$ A OCDE estabeleceu a população residente e a densidade demográfica como principal critério para classificar as regiões em três tipos: 1) regiões essencialmente urbanas com menos de $15 \%$ da população vivendo em comunidades rurais e densidade demográfica menos que 150 habitantes por $\mathrm{km}^{2}$; 2) regiões essencialmente rurais com mais de $50 \%$ da população vivendo em comunidades rurais e densidade demográfica inferior a 150 habitantes por $\mathrm{km}^{2}$; 3) regiões relativamente rurais em que 15 e $50 \%$ da população vivem em comunidades rurais e com menos de 150 habitantes por $\mathrm{km}^{2}$. 
de forma superior dos recursos da região, por estarem sendo subutilizados (capacidade ociosidade) ou utilizados de forma subótima (rendimento não maximizado); 3) as vantagens absolutas da região adquiridas através da divisão do trabalho e da especialização relativa ao seu entorno relevante.

Ainda, para o mesmo autor, "a especialização relativa de uma região vis-à-vis ao seu entorno relevante - vale dizer, àquele entorno no qual a região realiza a maior parte de sua produção e de sua demanda - é o principal indicador de sua potencialidade”. No entanto, na literatura de economia regional, estamos longe de ter um indicador suficiente e consensuado de especialização, bem como em torno de boas medidas de 'especialização potencial' ou de 'gargalos' para o desenvolvimento regional (PAIVA, 2004, p. 26).

Considerando o estudo e a identificação das potencialidades de uma região complexa, Paiva (2004, p. 11-12) propõe metodologicamente dois grandes momentos:

Primeiro momento: em que se opera com base em dados estatísticos secundários levantados, sistematizados e disponibilizados pelos mais diferentes institutos de pesquisa e instituições governamentais, com vistas a fornecer substrato empírico à identificação e à interpretação das condições de reprodução social e econômica dos habitantes, definindo um diagnóstico preliminar das potencialidades regionais; Segundo momento: onde se impõe a realização de uma pesquisa de campo, com levantamento primário de dados e informações, com vistas a testar a consistência e a economicidade das hipóteses sugeridas no primeiro momento.

O volume de dados existente em geral é expressivo o que envolve um esforço de hierarquização, seleção e descarte, para o qual Paiva (2004, p. 27) propõe: 1) buscar as informações sobre o que ele denomina de "macro-especializações regionais", entre os setores: a agropecuária, a indústria e os serviços; 2) resgatar as informações sobre a disponibilidade, qualidade, distribuição e do padrão de utilização/emprego dos fatores de produção, que em conjunto com o item anterior, fornecem pistas importantes sobre limites e possibilidades de reconversão produtiva regional; 3) construir indicadores sobre o padrão de internalização e distribuição do produto e da renda regionais, que fornece pistas sobre o tamanho do mercado interno e sobre o grau de endogeneização do excedente gerado na região.

O Quociente Locacional é a medida de especialização regional mais difundida em pesquisas voltadas à identificação da estrutura econômica e das potencialidades dos territórios. Ele busca confrontar a participação relativa 
de um determinado setor e/ou segmento produtivo na economia de uma REVISTA GRIFOS 65 dada região com participação relativa desse mesmo setor e/ou segmento em uma região de referência (normalmente, a macrorregião que engloba a primeira) (PAIVA, 2004, p. 36).

Para o desenvolvimento desse trabalho seguimos quatro passos:

1. Análise dos três macrossetores (agropecuária; indústria e serviços), buscando identificar o que é expressivo na região em termos absolutos (número de empregos ocupados, empregados) e relativos (maiores percentagens dos setores no PIB);

2. Identificação dos setores e subsetores "grandes" e dentre eles os grandes que são "básicos" ou exportadores, mas que são específicos da região. Para isso será utilizado Quociente Locacional (QL). Serão considerados apenas os maiores QLs. Estes segmentos com grandes QLs e com grande expressão absoluta (número de ocupados) e relativa (\% PIB - Produto Interno Bruto), serão considerados segmentoschaves. Os grandes QL's, porém de pouca expressão absoluta e relativa deverão ser analisados em separado, caso a caso, pois podem representar novos setores, ainda incipientes, mas promissores. No entanto, não desenvolvido por conta dos limites deste texto.

3. Identificação de possíveis encadeamentos. O encadeamento é central, pois onde há cadeia, há muito mais emprego do que aparece inicialmente. Além disso, onde há cadeia, há gargalo, e os custos de mobilização do segmento por unidade de benefício são muito reduzidos. A identificação dos gargalos depende de um trabalho de campo, não realizado aqui.

4. Hierarquização dos setores com algum potencial, pela alta expressão, alto QL, ou seja 'grau de potencial'. O potencial será maior quanto menor o número de gargalos e quanto mais fácil for superá-lo. Também se constitui em potencialização, quando o segmento-chave for intensivo em mão de obra, ou a criação desta é relativamente fácil, pois as bases estão dadas.

\section{A microrregião de Frederico Westphalen}

A microrregião de Frederico Westphalen possui uma área de $5.271 \mathrm{~km}^{2}$, com uma população de 180.174 habitantes em 2007, apresentando uma taxa de crescimento de $0,75 \%$ ao ano no período de 2000/2007 (tabela 1), constituída por 27 municípios, sendo: Alpestre, Ametista do Sul, Caiçara, Constantina, Cristal do Sul, Dois Irmãos das Missões, Engenho Velho, Erval Seco, Frederico Westphalen, 
${ }^{2}$ Para a maioria do conjunto de informações analisadas será considerado o total de 26 municípios, pois Novo Xingu por ser recém emancipado, ainda não apresenta dados sobre as informações menos recentes.
Gramado dos Loureiros, Iraí, Liberato Salzano, Nonoai, Novo Tiradentes, Novo Xingu, Palmitinho, Pinheirinho do Vale, Planalto, Rio dos Índios, Rodeio Bonito, Rondinha, Seberi, Taquaruçu do Sul, Três Palmeiras, Trindade do Sul, Vicente Dutra, Vista Alegre.

Dentre os 27 municípios da microrregião, 9 possuem menos de três mil habitantes. O município mais populoso dessa microrregião é Frederico Westphalen, que possui 27.308 habitantes, e o menos populoso é Engenho Velho, com 1.584 habitantes (IBGE, 2008).

Importante ressaltar a presença, em terras demarcadas, da população indígena, que pode estar contribuindo para o índice positivo de crescimento vegetativo e de permanência, nesse caso o município de Planalto e Trindade do Sul, e no caso de Nonoai pode estar reduzindo o impacto negativo, pois ficou com apenas $-0,56 \%$. Nos municípios de Rio dos Índios, Taquaruçu do Sul, o índice de perda da população $(13,18 \%$ e $17,92 \%$, respectivamente) foi maior devido às indenizações das terras inundadas e de terras destinadas a programas de preservação devido às obras das Usinas Hidrelétricas.

Dos 26 municípios $^{2}$ da microrregião, 14 possuem menos de $35 \%$ da população habitando o espaço urbano, sendo que apenas os municípios de Frederico Westphalen 76\%, Nonoai com 69\% e Rondinha com $68 \%$ podem ser considerados urbanos, para os padrões do brasileiros.

A ruralidade da microrregião de Frederico Westphalen pode ser caracterizada também utilizando-se os dados sobre pessoas de 10 anos ou mais de idade, economicamente ativas (ocupados e desocupados) no espaço rural, pois 19 dentre os 26 municípios da microrregião possuem mais de $50 \%$ da população ocupada (PO) no espaço rural, e apenas 6 possuem menos de $35 \%$ da $\mathrm{PO}$ no rural; portanto, os dados são muito semelhantes.

A população ocupada do espaço rural da microrregião é de $54 \%$ (98.477 pessoas), o que difere radicalmente da realidade do estado do Rio Grande do Sul, onde apenas 20\% (1.0362,44 pessoas) da população ocupada se encontram no espaço rural.

Conforme IBGE (2008), na microrregião de Frederico Westphalen, 49.319 (28,7\%) pessoas de 10 anos ou mais ocupadas na semana de referência, não possuíam rendimento, enquanto que, no estado do Rio Grande do Sul, este índice é de apenas 9,1\% (414.436 pessoas). Em 16 municípios, dos 26 analisados, o índice de pessoas ocupadas sem renda é superior à média da microrregião, sendo que Alpestre e Taquaruçu do Sul possuem mais de $50 \%$ da população ocupada sem rendimento, ficando caracterizado o alto grau de pobreza.

Outro dado que reforça a desigualdade e a pobreza é o percentual da população ocupada com rendimento superior a 3 salários mínimos, 
Grande do Sul é de 33,45\%. Nenhum município da microrregião alcança o índice estadual. $\mathrm{O}$ município com melhor índice é Frederico Westphalen, com $28,12 \%$, e o pior índice fica com o município de Alpestre, com apenas 7,54\% da população com rendimento superior a 3 salários mínimos.

O índice de desenvolvimento humano (IDH) ${ }^{3}$ da microrregião de Frederico Westphalen é de 0,725 levando-se em consideração a educação, longevidade e renda, enquanto que do Rio Grande do Sul é de 0,814 e do Brasil é de 0,725. O indicador que mais difere e impacta negativamente no índice da microrregião é o IDH da renda de 0,617, enquanto do Rio Grande do Sul é de 0,754 e do Brasil 0,723. Somente os municípios de Frederico Westphalen e de Rondinha têm o IDH da renda acima de 0,700 . Isto confirma a microrregião como uma das áreas economicamente deprimidas inclusa à região Noroeste do Rio Grande do Sul e comparada a mesorregião Grande Fronteira do Mercosul, da qual faz parte, cujas características socioeconômicas são similares. No IDH da educação de 0,520, o município de Planalto se destaca com o menor índice, e a causa pode ser atribuída à políticas educacionais pouco desenvolvidas/inadequada para a população indígena remanescente.

A economia está alicerçada na produção agropecuária, pois 53,8\% do total da população ocupada encontra-se neste setor econômico, que apresenta um valor agregado bruto de $\mathrm{R} \$ 625.954$ (mil), ou seja, $34,85 \%$ do Valor Acrescentado Bruto (VAB) total, enquanto no Estado o VAB agropecuário é de apenas $11,96 \%$ do total. A situação se inverte para o setor econômico da indústria, onde a microrregião apresenta um VAB de apenas 22,11\%, enquanto no Estado este índice chega a $41 \%$, e a população ocupada da microrregião neste setor é de $14,9 \%$ e no estado chega a $24,42 \%$. No setor de serviços, os índices do VAB encontram-se mais equilibrados entre a microrregião e o Estado, com 43,03\% e $47,11 \%$, respectivamente. No entanto, a diferença aumenta para a população ocupada neste setor econômico, pois no Estado atinge 55,49\%, enquanto na microrregião chega apenas a $31,3 \%$.

Em 2000, o setor industrial da microrregião de Frederico Westphalen era constituído de 429 estabelecimentos industriais, dos quais, 46 estabelecimentos $(10,7 \%)$ transformam produtos primários da agropecuária, como: produtos de origem animal (reses, suínos, aves, leite), de origem vegetal (grãos, frutas e legumes). O setor madeireiro assume posição de destaque, pois é constituído por 96 estabelecimentos, que representam $22,4 \%$ do total. Também o setor metal mecânico apresenta um significativo conjunto de estabelecimentos, participando com $16,3 \%$ do total (70 estabelecimentos). 
Neste setor, a atividade principal das pessoas com 10 anos ou mais de idade, ocupadas na semana de referência, apenas 1,6\% encontrava-se na indústria extrativa e distribuição de eletricidade gás e água, 9,3\% se encontram na indústria de transformação e 3,9\% estavam na construção (ver tabela 5). Cabe destacar que, do total de 2.680 pessoas da indústria extrativa, 1.040 pessoas, ou seja, 38,8\% se encontravam em Ametista do Sul, e dos 25 estabelecimentos industriais de transformação deste município 22 são de lapidação de pedras preciosas e semipreciosas. Esses 22 estabelecimentos industriais, no entanto, nesta classe de Classificação Nacional de Atividades Econômicas (CNAE), em 2003, empregavam apenas 101 pessoas, a partir do qual se pode supor a existência de muito trabalho informal.

Dos 429 estabelecimentos industriais de transformação desta microrregião, 112, ou seja, 26,1\% encontram-se no município de Frederico Wetesphalen. Os demais municípios com significativo número de estabelecimentos são: Planalto (33), Constantina (30), Rodeio Bonito (31), Seberi (26), Ametista (25), Iraí (23) e Palmitinho (20).

Das classes CNAE dos estabelecimentos industriais de transformação, algumas se caracterizam pela maior distribuição entre os municípios, como o dos estabelecimentos agropecuários, confecções, madeireiro, calçadista, enquanto outros se apresentam concentrados, como o caso dos de pedras preciosas.

O setor de serviços está caracterizado pela distribuição mais uniforme dos empregos, que representam $31,3 \%$ da população ocupada da microrregião. Nesse setor a atividade principal das pessoas de 10 anos ou mais de idade, ocupados na semana de referência, estão distribuídos da seguinte forma: comércio, representação de veículos automotores, objetos pessoais e domésticos, com 9,3\%; alojamento e alimentação com 1,8\%; transporte, armazenagem e alimentação com $2 \%$; intermediação financeira e atividade imobiliária, aluguéis e serviços prestados com 2,2\%; administração pública, defesa e seguridade social com $3,5 \%$; educação com $4,2 \%$; saúde e serviços sociais com $1,2 \%$ e outros serviços coletivos sociais e pessoais com 1,7\%. Essa distribuição mais uniforme se deve ao caráter básico dos serviços e sua proporcionalidade com o tamanho da população. Cabe destacar que na classe de CNAE, do setor de serviços, a administração pública em geral detém $39 \%$ do número total de empregados.

O setor agropecuário, além dos indicadores já apontados anteriormente, aparece como setor importante da economia da microrregião, pois ocupa uma área total de 391.713ha, distribuídos entre 20.525 estabelecimentos rurais, o que define uma área média de 15,8ha por estabelecimento. Portanto, a agropecuária se caracteriza fundamental- 
mente como do tipo familiar de produção diversificada, como será REVISTA GRIFOS 69

explanado a seguir. A área de lavoura está constituída de 246.230ha, que representa $48 \%$ do total. A lavoura está presente em $100 \%$ dos estabelecimentos; com uma área média de 7,2ha para cultivo, enquanto a área com pastagens para a criação é de $71.520 \mathrm{ha}$, sendo praticada por 16.204 estabelecimentos rurais, com área média de 4,4ha por estabelecimento, que representa $28 \%$ da área média.

A limitada infraestrutura produtiva perceptível pelo reduzido número de tratores, apenas $3.271 \mathrm{em} 2.833$ estabelecimentos rurais, ou seja, $11,2 \%$ das propriedades, o que reforça ainda mais o caráter familiar da agricultura da microrregião. A pecuária também esta limitada à pequenas dimensões, pois o rebanho total da microrregião é 295.765 cabeças para 20.525 estabelecimentos rurais, com uma área média de 14,4 cabeças por estabelecimento. Considerando uma área média de pastagem de 4,4ha. Por estabelecimento rural, temos uma média de 3,3 cabeças por ha, o que pode ser considerado uma boa intensidade de exploração.

Dentre as atividades pecuárias, destacam-se a bovinocultura, especialmente de leite, a suinocultura e avicultura. Portanto, na microrregião o macrossetor que se destaca é o agropecuário, tanto pelo pessoal ocupado quanto pelo PIB, e neste setor as atividades principais na agricultura são: o binômio soja/trigo, nas áreas planas e mecanizáveis e nas áreas de relevo mais acidentado e de difícil mecanização se destacam as culturas do fumo, da mandioca e vem ganhando espaço a fruticultura de clima temperado e tropical. Na pecuária, destacam-se a suinocultura, avicultura e bovinocultura de leite, nas propriedades de menor mecanização e de relevo acidentado, enquanto a bovinocultura de corte nas áreas mais planas.

No macrossetor indústria, destaca-se, principalmente o têxtil, com confecções de peças de vestuário, exceto roupas íntimas, blusas e calças, o setor madeireiro com destaque para a fabricação de móveis com predominância em madeira e desdobramento em madeira e no setor extrativo a lapidação de pedras preciosas e semipreciosas.

Nos serviços destacam-se os de necessidades básicas, como os de saúde, educação, bancários, comércio varejista e atacadista, de representação e os serviços de automecânica.

\section{Potencialidades e limites para o desenvolvimento econômico da microrregião de Frederico Westphalen}

No macrossetor de serviços os maiores valores de QLs da microrregião de Frederico Wetesphalen se apresentam como suporte 
complementar ao setor industrial, como madeireiro, fabricação de móveis e outros materiais $(2,9526)$ e representações comerciais e agentes de comércio de madeira $(2,3579)$. No setor calçadista - comércio atacadista de calçado, com 4,6069 de QL. No comércio atacadista de produtos químicos com QL de 3,1607. Destaca-se também a educação superior, com o QL de 9,4363, do transporte aquaviário urbano com QL de 27,8511. Ainda no setor de serviços cabe referenciar o grupo relacionado ao setor agrícola com QLs destacados como: crédito cooperativo com 6,6252; aluguel de máquinas e equipamentos agrícolas, com QL de 11,6468; comércio atacadista de animais vivos com 6,6354; comércio atacadista de leite e produtos do leite com QL de 3,8531 e comércio atacadista de cereais e leguminosas, farinhas, amidos e féculas com 3,4861 de QL.

Quanto ao macrossetor indústria destacam-se os QLs de fabricação de artefatos de tanoaria com 3,5609; reprodução de discos e fitas com 12,9247; reprodução de softwares em disquetes e fitas com 48,4676; fabricação de produtos cerâmicos não refratários com 3,8421; fabricação de tanques e reservatórios metálicos com 8,5114; fabricação de baterias e acumuladores com 20,5055; fabricação de cabines, carrocerias e reboques com 9,3235; manutenção e reparo de aparelhos com 5,2397; fabricação de tratores agrícolas com 36,0540; fabricação de motores estacionários com 60,7996; fabricação de outras máquinas e equipamentos com 5,6856; fabricação de máquinas e equipamentos com 7,7196; fabricação de equipamentos de transmissão com 1,4808; fabricação de farmoquímicos com 2,7775; preparo de especiarias, molhos e temperos com 56,0070; beneficiamento moagem com 6,1446; fabricação de produtos lácteos com 6,7049 e preparo do leite com 4,2548.

Com relação ao macrossetor agrícola, dentre as culturas anuais que apresentam QLs destacados estão: a cultura da mandioca com 3,8194, ficando classificada em $4^{\circ}$ lugar no estado; milho, com 1,8551, ficando em $8^{\circ}$ lugar entre as regiões; o binômio soja e trigo, com 1,0330 e 1,4133 , respectivamente, ficando em $15^{\circ}$ e $14^{\circ}$ lugares entre as microrregiões. Nas culturas permanentes destacam-se a produção de abacaxi com 1,29, de QL; tangerina com 1,9597; nozes, com 1,9766; uva, com 0,5439, e laranja, com 2,6357, ficando classificadas entre as 35 microrregiões em $4^{\circ}, 7^{\circ}, 8^{\circ}, 12^{\circ}$ e $14^{\circ}$, respectivamente.

Na pecuária destacam-se os QLs de suínos, com 2,09; frango, com 0,39 ; leite, com 1,14 e ovos, com 0,65 , que correspondem ao $5^{\circ}$, $11^{\circ}, 14^{\circ}$ e $13^{\circ}$ lugar respectivamente entre as microrregiões do estado.

Analisando os QLs de forma isolada nos macrossetores podemos observar o que segue: no macrossetor serviços, nenhuma das atividades com maior QL apresenta potencial, a priori e por si, de consti- 
tuir-se em carro-chefe e em produto de exportação capaz de desencaREVISTA GRIFOS 71 dear um processo de desenvolvimento diferenciado. No macrossetor indústria, a situação difere do setor de serviços, pois aparecem várias classes CNAE com QLs muito altos. À primeira vista, parece que este macrossetor se constitui ainda apenas como complementar ou subsidiário ao de regiões do seu entorno, que precisam ser estudas em conjunto. Neste setor (industrial), que a partir dos seus altos QLs precisam ser mais e melhor investigados, é o caso da reprodução de discos e fitas e a reprodução de software. No macrossetor agrícola, os QLs dos produtos tradicionais da pecuária que se destacam são suínos, aves e leite. No entanto, com efetivo potencial de expansão e geração ou mesmo manutenção da população no espaço rural, destaca-se a atividade leiteira. Nas culturas temporárias aparece com potencial a cultura da mandioca, pois também apresenta um pequeno desenvolvimento no setor industrial e de serviços. Considerando as condições climáticas, as frutas cítricas como a laranja e a tangerina também aparecem com possíveis potenciais, mas precisam ser analisadas com mais profundidade. Os microclimas possibilitam a antecipação de colheitas de frutas, principalmente da uva, que pode ser colhida no mês de novembro, quase dois meses antes que a da Serra Gaúcha. Isto lhe dá um diferencial no mercado, que é responsável pela melhoria da situação econômica de um conjunto de produtores rurais. No entanto, a uva é comercializada de forma in natura e não explorada nas formas industriais para agregação de valor e melhoria de renda na região, assegurando a criação de empregos. É importante que se leve em consideração nas análises de futuro que nesta microrregião vem se intensificando o uso potencial dos recursos hídricos com instalações de barragens no rio Uruguai e seus afluentes, tais como Usina Hidrelétrica (UHE) Foz do Chapecó, Pequena Central Hidrelétrica $(\mathrm{PCH})$ Manjolinho, UHE Itapiranga, UHE Itá, entre outras. Porém, se de um lado contribui para o êxodo de agricultores para outras regiões do Brasil, pelo reassentamento, de outro, pode se apresentar como um fator potencial para o desenvolvimento econômico da região, na medida em que novos setores podem ser estimulados como o agroturismo, ecoturismo, turismo de lazer, piscicultura de água doce, além do ingresso dos recursos diretos da exploração das reservas de água.

Citando como parâmetro de investimentos, a implantação da Usina Hidrelétrica Foz do Chapecó envolverá investimentos no total de $\mathrm{R} \$ 2$ bilhões, com a geração de 2.500 empregos diretos no pico das obras e mais 3.000 empregos indiretos. Prega-se que a economia local será impulsionada e as administrações municipais serão beneficiadas com maior arrecadação de Imposto sobre Circulação de Mercadorias 

2005 para os municípios de Alpestre com área inundada de 787,0ha é de $\mathrm{R} \$ 1.146 .020,72$. Nonoai com 227,0 ha é de $\mathrm{R} \$ 330.554,90$ e Rio dos Índios com área inundada de 800,0 ha é de $\mathrm{R} \$ 1.164 .951,17$. Serão atingidos sete municípios gaúchos e seis catarinenses, mais cinco terras indígenas. Observamos, ainda, que se encontra em estágio avançado de construção a represa do Monjolinho, no rio Passo Fundo, município de Nonoai e também, atividades de levantamentos topográficos para a construção de mais duas UHE no trajeto do Rio Uruguai, até Itapiranga, atingindo vários municípios da microrregião de Frederico Westphlalen.

\section{Considerações finais}

Inicialmente cabe considerar que a microrregião de Frederico Westphalen apresenta significativas disparidades internas, próprias do atual modelo de desenvolvimento urbano-industrial, agravadas por se caracterizar como uma região ainda efetivamente rural, visto que apenas um dos 26 municípios possui mais de 20 mil habitantes e 22 municípios possuem menos de 10 mil habitantes. Dentre as principais marcas desse processo de desenvolvimento destacam-se: o baixo IDH $(0,725)$; o êxodo rural $(-0,6 \%)$; fortes indicadores de pobreza $(28,7 \%$ de pessoas ocupadas sem rendimento), em especial nas áreas rurais e; conflitos sócioambientais (populações indígenas e as Barragens).

Do ponto de vista econômico, a região pode ser considerada agrícola, pois envolve aproximadamente $35 \%$ do VAB e $54 \%$ da população ocupada, ainda alicerçada no trinômio soja/trigo/milho. No entanto, podem-se observar o importante crescimento na pecuária, a produção de leite, suínos e aves para a agroindústria. Outro setor agrícola em expansão é o da produção de frutas, principalmente da uva, beneficiada pelo fator climático que possibilita a colheita antes da Serra gaúcha. Dependendo das políticas regionais de desenvolvimento poderá constituir-se em relevante potencial.

A construção das usinas hidrelétricas vem gerando a expectativa de que o setor de serviços em geral, em especial o comércio, se amplie e por consequência possa atrair processos de investimentos industriais na região, além do turismo.

Considerando a análise dos três macrossetores econômicos, evidenciam-se as limitações do setor de serviços e da indústria, no atual contexto, para impulsionarem um novo processo de desenvolvimento na microrregião, muito embora alguns de seus subsetores apresentem 
QL's altos. Isto se reforça na media em que não se pode identificar um REVISTA GRIFOS 73 encadeamento dos setores econômicos, nem mesmo em algum de seus subsetores. Buscando hierarquizar setores potencialmente propulsores no processo de desenvolvimento, fica evidente que o setor agropecuário ainda apresenta as melhores condições, diante de todos os limites identificados.

Cabe ressaltar as observações já feitas sobre os limites deste estudo, tanto em seu propósito (realizar uma análise parcial dos dados secundários) quanto em suas condições concretas (impossibilidade de realização do trabalho de campo, segundo momento da proposta metodológica).

Mesmo assim, foi possível identificar através dos dados, indicadores significativos para o aprofundamento dos estudos e discussões com os atores locais, bem como, a importância e a necessidade do trabalho in loco como propõe a metodologia (PAIVA, 2004), contribuindo na compreensão do encadeamento existente na região em estudo, bem como o desejo e as intenções dos principais atores envolvidos com as atividades mais promissoras, apontadas pelos dados secundários.

Portanto, no contexto atual, pensar desenvolvimento a partir de realidades rurais já não parece mais uma heresia. No entanto, permanece como um amplo campo de estudo e descoberta as diferentes formas capazes de realizá-lo de modo não excludente.

\section{Referências}

ABRAMOVAY, R. Funções e medidas da ruralidade no desenvolvimento contemporâneo. In: ABRAMOVAY, R. (Org.). O futuro das regiões rurais. Porto Alegre: UFRGS, 2003.

FEE - FUNDAÇÃO DE ECONOMIA E ESTATISTICA. FEE dados. Disponível em: <www.fee.tche.br/dados>. Acesso em: 10 fev. 2008.

IBGE - INSTITUTO BRASILEIRO DE GEOGRAFIA E ESTATISTICA. Censo 2000. Disponível em: <www.ibege.com.br> . Acesso em: 15 fev. 2008.

PAIVA, Carlos Águedo Nagel. Como identificar o potencial de desenvolvimento endógeno de uma região? Porto Alegre: FEE, 2004. (Documento FEE, n. 59).

. O que é uma região de planejamento com vistas ao planejamento do desenvolvimento endógeno regional. In: PRIMEIRAS JORNADAS DE ECONOMIA REGIONAL COMPARADA, 2005, Porto Alegre. Anais... Porto Alegre: FEE/PUC - RS, 2005. 1CD - ROM. 
PNUD - PROGRAMA DAS NAÇÕES UNIDAS PARA O DESENVOLVIMENTO. Atlas de desenvolvimento humano - IDH. Metodologia, 2003.

VEIGA, J. E. Mudanças nas relações entre espaços rurais e urbanos. G\&DR, v. 3, n. 1, p. 123-149, jan./abr. 2007.

\begin{abstract}
The article on the development of Frederico Westphalen Mesorregião (RS), was constructed from a methodology and its applicability, allowing the understanding and identification of potential bottlenecks and the development process, as well as the reflection of local authors. To understand the issues, treat the region as a stage of local development and practical existence of a potential for endogenous development in rural areas from the analysis of the three macro-sectors (agriculture, industry and services), the identification of sub-sectors "large" and those considered the "basic" or with export potential, but are specific to the region, which is used for the Locacional Ratio - QL, the identification of possible threads and the ranking of sectors with a potential for high QL expression of, or potential exporter and impulcionador the endogenous dynamics of the local economy. The micro has an area of $5,271 \mathrm{~km}^{2}$ with a population of 180,174 inhabitants in 2007 , showing a growth rate of $0.75 \%$ a year in $2000 / 2007$, consists of 27 municipalities, which have been identified in this study the potential and limits to economic development. The analysis of QLS, suggests the region as primarily agricultural, activities with the potential for endogenous development (specific) production and socioeconomic differential.
\end{abstract}

Keywords: development, methodology, potential. 